\title{
Control effect on cotton aphids of insecticides sprayed with unmanned aerial vehicles under different flight heights and spray volumes
}

\author{
Hongyan $\mathrm{Hu}^{1,2}$, Xiangliang $\mathrm{Ren}^{1,2}$, Xiaoyan $\mathrm{Ma}^{1,2}$, Huanhuan $\mathrm{Li}^{3}$, Yajie $\mathrm{Ma}^{1,2}$, \\ Dan Wang ${ }^{1,2}$, Xianpeng Song ${ }^{1,2}$, Yanhua Meng ${ }^{3,4^{*}}$, Yan $\mathrm{Ma}^{1,2^{*}}$ \\ (1. Zhengzhou Research Base, State Key laboratory of Cotton Biology, Zhengzhou University, Zhengzhou, 4550001, China; \\ 2. State Key laboratory of Cotton Biology, Institute of Cotton Research, Chinese Academy of Agricultural Sciences, Anyang, 455000, China; \\ 3. Anyang Institute of Technology, Anyang, 455000, China; \\ 4. Key laboratory of Aviation Plant Protection, Ministry of Agriculture and Rural Affairs, Anyang 455000, China)
}

\begin{abstract}
Unmanned aerial vehicles (UAVs) are an emerging technology increasingly used to control plant diseases and pests in China. However, the efficacy of UAV spraying in cotton fields remains unclear. This paper assesses the droplet deposition of UAV spraying and analyzes how flight heights and spray volumes affect aphids control in cotton fields. Allura red was used as a tracer and Kromekote cards were used to collect the droplets. The research results demonstrated that droplet uniformity, droplet coverage, and droplet density were all higher at a flight height of $1.5 \mathrm{~m}$ and a spray volume of $22.5 \mathrm{~L} / \mathrm{ha}$. Control efficacy on the first day after spraying was correlated with the number of droplets deposited on the underside of leaves, and higher droplet coverage and density resulted in better pest control. Optimal control efficacy on the seventh day after spraying was achieved at the flight height of $1.0 \mathrm{~m}$ and $1.5 \mathrm{~m}$, with control efficacy rates ranging from $57.93 \%$ to $80.53 \%$. Field trials of five different insecticides verified the efficacy of UAV spraying controls against cotton aphids. These results provide a theoretical reference and technical support for subsequent UAV spraying to control for diseases and pests.
\end{abstract}

Keywords: unmanned aerial vehicle, flight parameter, spray volume, droplet deposition, cotton aphids DOI: $10.33440 /$ j.ijpaa.20210401.161

Citation: Hu H Y, Ren X L, Ma X Y, Li H H, Ma Y J, Wang D, et al. Control effect on cotton aphids of insecticides sprayed with unmanned aerial vehicles under different flight heights and spray volumes. Int J Precis Agric Aviat, 2021; 4(1): 44-51.

\section{Introduction}

Cotton (Gossypium spp.) is a major commercial crop in China, providing significant income for farmers and contributing to the national economy. However, in recent years, cotton planting areas in China have declined, from 4524 thousand hectares in 2011 to 3339.2 thousand hectares in 2019 (Data from the National Bureau of Statistics of China) due to high labor costs, low mechanization rates, and diseases and pests ${ }^{[1]}$. The cotton aphid Aphis gossypii Glover is a sap-sucking insect that gathers on the underside of cotton leaves and can cause serious damage during the seedling and square-boll stages of cotton development. This species has become a major

Received date: 2021-02-20 Accepted date: 2021-03-22

Biographies: Hongyan $\mathrm{Hu}, \mathrm{PhD}$, Associate Professor, research interests: agricultural aviation application and plant protection, Email: huhongyan1986@ 163.com; Xiangliang Ren, $\mathrm{PhD}$, Associate Professor, research interests: agricultural entomology and pest control, Email: renxiangliang@163.com; Xiaoyan Ma, PhD, Professor, research interests: weed control and management, Email: maxy_caas@126.com; Huanhuan Li, PhD, Lecturer, research interests: chemical synthesis and pest \& disease management, Email: greatwomen407@ 163.com; Yajie Ma, Assistant Professor, research interests: agricultural entomology and pest control, Email: yun1268486@126.com; Wang Dan, Assistant Professor, research interests: agrochemical research and application, Email: nywangdan@sina.com; Xianpeng Song, assistant professor, research interests: agrochemicals research and application, Email: sxp15294@126.com. *Correspondence author: Yan Ma, Professor, research interests: agrochemical research and application. Mailing address: Institute of Cotton Research of the Chinese Academy of Agricultural Sciences, Anyang, 455000, China. aymayan@126.com. Yanhua Meng, PhD, research interests: precision agricultural aviation application and pests \& disease management. Mailing Address: Anyang Institute of Technology, Anyang. Email: yanhua.meng@outlook.com. cotton pest since the widespread planting of transgenic Bt cotton in northern $\mathrm{China}^{[2]}$. Currently, cotton aphids are primarily controlled by applying large amounts of chemicals from the ground with a boom sprayer or a backpack sprayer. During the seedling stage, cotton plants are short and their leaves are small, resulting in low leaf area indexes (LAI). This often means that cotton plants have low rates of pesticide utilization when a large-volume sprayer is used, which typically leads to pesticide overuse ${ }^{[3]}$. Cotton leaves overlap during the square-boll stage, making it difficult for a conventional ground-based machine to effectively operate in the field ${ }^{[4]}$. Moreover, these large-volume ground-based sprayers can easily harm plants when used in cotton fields, which can lead to pesticide losses and environmental pollution ${ }^{[5,6]}$. Spraying with a manual backpack sprayer has several drawbacks, including high labor intensity, low efficiency, and high rates of pesticide exposure $^{[7,8]}$. Therefore, it is necessary to develop an autonomous, affordable, and highly efficient sprayer to apply pesticides in cotton fields.

In recent years, unmanned aerial vehicles (UAVs) have increasingly been used to combat crop disease and manage pests ${ }^{[9-11]}$. UAVs have several advantages compared to a manned agricultural helicopter, the most important of which is their ability to take off and land in small areas without requiring a special airport ${ }^{[12]}$ This makes UAVs better for spraying at low altitudes, especially in difficult-to-access areas ${ }^{[13]}$. UAVs are more flexible and effective during the operation compared with conventional ground-based sprayers $^{[14]}$. Furthermore, UAVs do not require a lot of labor and are extremely efficient. Additionally, the downwind generated by UAV rotors could result in better droplet penetrability and deposition $^{[15]}$. China is a large agricultural country with complex 
topography, and the demand for aviation use in precision agriculture aviation is increasing. The use of UAV technology to manage diseases and pests in crops will increase working efficacy, reduce labor intensity, and promote the overall development of modern agriculture.

Aerial spraying is complicated, and previous research has explored factors that influence the distribution and deposition of droplets, including wind speed, droplet size, nozzle type, and plant shape ${ }^{[16-19]}$. The operation parameters of UAVs also affect droplet deposition. Hussain et al. used an unmanned aerial agro-chemical spraying (UAAS) system to study how flight height and nozzle opening size affected spray deposition and uniformity on wheat crops. They found that this system provided adequate uniformity and coverage at an operating height of $1.5 \mathrm{~m}$ with the spray nozzle $50 \%, 75 \%$, and $100 \%$ open $^{[20]}$. To improve UAV spraying performance, Ahmad et al. compared droplet deposition in target and off-target zones and found that the average deposition in the target zone was highest when the flight velocity was $2 \mathrm{~m} / \mathrm{s}$ and the flight height was $2 \mathrm{~m}$, while deposition in the off-target zone was negligible for single-rotor $\mathrm{UAVs}^{[10]}$. For research related to UAV control efficacy, Qin et al. investigated how applying HyB-15L drone pesticides affected droplet deposition and its control effect on brown rice plant hoppers, and found that UAV efficiency at a flight height of $1.5 \mathrm{~m}$ and a flight velocity of $5 \mathrm{~m} / \mathrm{s}$ performed better than conventional sprayers ${ }^{[15]}$. Gao et al. tested three UAV spray heights $(1,2.5$, and $5 \mathrm{~m})$ above maize crops and determined that a flight height of $2.5 \mathrm{~m}$ provided the best protection against the corn borer pest ${ }^{[21]}$. Menechini et al. used aerial application to study the effects of four spray volumes $(7.5,13.5,20.0$, and $30.3 \mathrm{~L} / \mathrm{ha})$ on wheat crops and found that coverage was highest at spray volume of $30.3 \mathrm{~L} / \mathrm{ha}^{[22]}$. Wang et al. studied how different UAV spray volumes $(9.0,16.8$, and $28.1 \mathrm{~L} / \mathrm{ha})$ affected droplet deposition and determined that a low spray volume of $9.0 \mathrm{~L} /$ ha resulted in lower deposition and control efficacy against wheat aphids and powdery mildew ${ }^{[23]}$. The results determined that spray parameters such as flight height and spray volume significantly affected droplet deposition and control efficacy. Wang et al. analyzed the control efficacy of $22 \%$ sulfoxaflor SC sprayed by drone on cotton aphids to study cotton pest control ${ }^{[24]}$. To identify suitable pesticides that target cotton aphids and can be deployed by UAVs, Wu et al. evaluated the efficiency of different pesticides sprayed by UAVs in cotton fields ${ }^{[25]}$. Sha et al. optimized UAV operation parameters and studied the efficiency of imidacloprid on cotton aphids ${ }^{[26]}$. In conclusion, little is known about how UAV flight height and spraying volume affect droplet deposition and distribution and control efficacy in cotton fields.

Therefore, this study will explore how different flight heights and spray volumes affect droplet distribution and control efficacy when insecticides are sprayed with UAVs to combat cotton aphids.

\section{Materials and Methods}

\subsection{Experimental Field}

Field trials were conducted in the experimental farm of the Institute of Cotton Research of the Chinese Academy of Agricultural Sciences (Anyang, Henan Province, China) $\left(36^{\circ} 05^{\prime} 05^{\prime \prime} \mathrm{N}\right.$, $114^{\circ} 30^{\prime} 59^{\prime \prime} \mathrm{E}$ ). The cotton variety CCRI 79 (3-5 leaves) was used at the seedling stage. The cotton was planted on 20 April 2019 and 24 April 2020. The row and plant spacing were $0.80 \mathrm{~m} \times 0.40 \mathrm{~m}$, respectively, and the plant density was 55,000 plants/ha. The respective plant height and LAI were $(13.83 \pm 0.17) \mathrm{cm}$ and 0.15 in
2019, and (11.05 \pm 0.23$) \mathrm{cm}$ and 0.13 in 2020. The weather conditions were recorded at $1.5 \mathrm{~m}$ above the top of the cotton by a hand-held wind gauge (PEAKMETER PM6252A, Shenzhen Huayi Instrument Technology Co., Ltd, China). During the 2019 spraying test, the field temperature, humidity, and wind speed were $28.3^{\circ} \mathrm{C}$ $33.5^{\circ} \mathrm{C}, 30.5 \%-39.5 \%$, and $1.2-2.8 \mathrm{~m} / \mathrm{s}$, respectively. In 2020 , the meteorological conditions were as follows: field temperatures of $24.5^{\circ} \mathrm{C}-29.9^{\circ} \mathrm{C}$, relative humidity of $35.2 \%-46.6 \%$, wind speed of $1.0-2.6 \mathrm{~m} / \mathrm{s}$.

\subsection{UAV and Manual Sprayer}

A four-rotor UAV 3WQFTX-10 with a spraying platform (Figure 1, Anyang Quanfeng Aviation Plant Protection Technology Co. Ltd., China) was used as an aerial sprayer. The total weight of the UAV was $12 \mathrm{~kg}$. The spraying platform consisted of a tank with a $10 \mathrm{~L}$ capacity, a miniature straightway pump, pipeline, spraying nozzle, and an electronic control valve. Four spraying nozzles (LU-120-015, Lechler Inc. Metzingen, Germany) were vertically installed below the four rotors of the UAV at $930 \mathrm{~mm}$ intervals. The pressure during the spraying experiment was $0.3 \mathrm{MPa}$, the nozzle flow rate was $2.2 \mathrm{~L} / \mathrm{min}$, and the spraying swath was $4.0 \mathrm{~m}$. Both the accuracy of the flight height and the velocity could be controlled within $0.2 \mathrm{~m}$ and $0.3 \mathrm{~m} / \mathrm{s}$, respectively, using Global Positioning System (GPS) technology.



Figure 1 Unmanned Aerial Vehicle (3WQFTX-10) sprayer used in this test

A MATABI Super Green16 (GOIZPERS Co., Ltd, Basque town, Spain), which is a manual air-pressure knapsack (MAP) sprayer, was selected as a control to apply pesticides to cotton plants. This sprayer is held on the back of the operator, with the hand lance and chamber attached to a long hose. The MAP sprayer has a pesticide tank with a $16.8 \mathrm{~L}$ capacity and a total weight of $3.7 \mathrm{~kg}$. The pressure during the spraying experiment was $0.3 \mathrm{MPa}$, while the flow rate was $0.8 \mathrm{~L} / \mathrm{min}$. The nozzle output spray volume was approximately $450 \mathrm{~L} / \mathrm{ha}$.

\subsection{Insecticide}

The seven pesticides used in this study were produced by six companies. Imidacloprid SC $(600 \mathrm{~g} / \mathrm{L})$ and beta-cypermethrin EC (4.5\%) were produced by Anyang Quanfeng Biological Technology Co., Ltd., China. Thiamethoxam WDG (25\%) was produced by Syngenta AG., Swiss. Sulfoxaflor WDG $(50 \%)$ was produced by Dow Agro Sciences LLC, USA. Flonicamid-acetamiprid WDG (46\%) was produced by Sino-Agri Leading Biosciences Co., Ltd., Tianjin, China. Carbosulfan EC (20\%) was produced by FMC Crop Protection Co., Suzhou, China. Bifenthrin EW (10\%) was produced by Jiangsu Sword Agrochemicals Co., Ltd., Huaian, China. 


\subsection{Experimental Design}

To assess UAV spray performance, $600 \mathrm{~g} / \mathrm{L}$ of imidacloprid

SC (45 g a.i./ha) mixed with $4.5 \%$ beta-cypermethrin EC ( $27 \mathrm{~g}$ a.i./ha) were applied in cotton field on 24 May 2019. The experiment consisted of ten treatments (nine with a UAV sprayer and one with an MAP sprayer) and one control (Table 1). Each treatment was conducted in a $16 \mathrm{~m} \times 90 \mathrm{~m}$ area, with a $10 \mathrm{~m}$ buffer zone between adjacent treatments (Figure 2). UAV spraying treatments were conducted at three flight heights $(1.0,1.5$, and $2.0 \mathrm{~m})$ and three spray volumes $(30.0,22.5$, and $18.0 \mathrm{~L} / \mathrm{ha})$. The spray volumes changed as flight velocity increased $(3,4$, and $5 \mathrm{~m} / \mathrm{s})$, while the nozzle flow rate remained constant. Each treatment was comprised of three replicates.

Table 1 The information of treatments

\begin{tabular}{|c|c|c|c|c|c|c|}
\hline \multirow{2}{*}{ Treatment } & \multicolumn{2}{|c|}{ Dosage (a.i. g/ha) } & \multirow{2}{*}{$\begin{array}{l}\text { Flight height } \\
(\mathrm{m})\end{array}$} & \multirow{2}{*}{$\begin{array}{l}\text { Spray volume } \\
\text { (L/ha) }\end{array}$} & \multirow{2}{*}{$\begin{array}{l}\text { Flight velocity } \\
\qquad(\mathrm{m} / \mathrm{s})\end{array}$} & \multirow{2}{*}{ Spray equipmen } \\
\hline & imidacloprid & beta-cypermethrin & & & & \\
\hline $\mathrm{T} 1$ & 45 & 27 & 1.0 & 30.0 & 3 & UAV \\
\hline $\mathrm{T} 2$ & 45 & 27 & 1.0 & 22.5 & 4 & UAV \\
\hline $\mathrm{T} 3$ & 45 & 27 & 1.0 & 18.0 & 5 & UAV \\
\hline $\mathrm{T} 4$ & 45 & 27 & 1.5 & 30.0 & 3 & UAV \\
\hline T6 & 45 & 27 & 1.5 & 18.0 & 5 & UAV \\
\hline $\mathrm{T} 7$ & 45 & 27 & 2.0 & 30.0 & 3 & UAV \\
\hline $\mathrm{T} 8$ & 45 & 27 & 2.0 & 22.5 & 4 & UAV \\
\hline T9 & 45 & 27 & 2.0 & 18.0 & 5 & UAV \\
\hline $\mathrm{T} 10$ & 45 & 27 & - & 450 & - & MAP \\
\hline
\end{tabular}

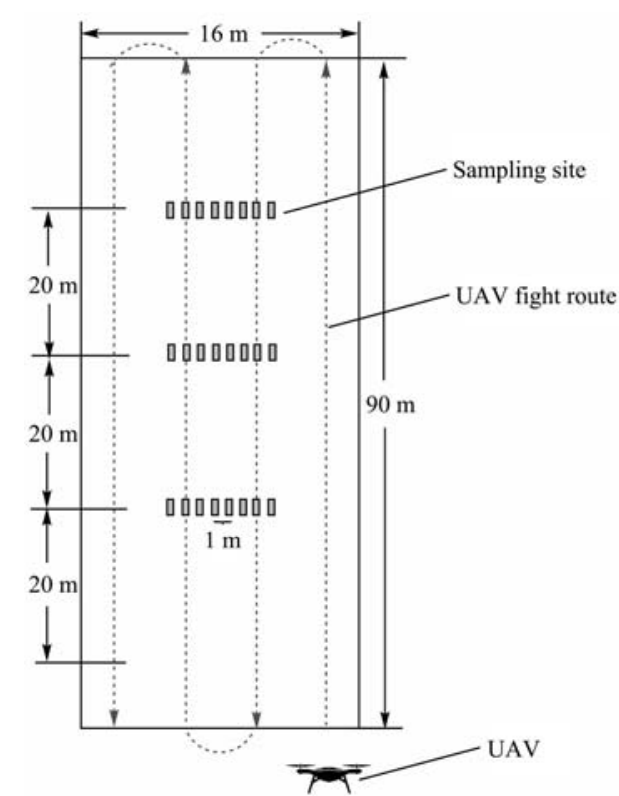

Figure 2 Sample point layout of every UAV test (top view)

To further verify the effects of UAV spraying, five treatments were arranged in the experimental cotton field on 24 May 2019 and 20 May 2020. Five insecticides commonly used to control cotton aphids were sprayed by UAV at a flight height of $1.5 \mathrm{~m}$ and a spray volume of $22.5 \mathrm{~L} / \mathrm{ha}$ : thiamethoxam (75 g a.i./ha), sulfoxaflor (75 g a.i./ha), flonicamid acetamiprid (55.2 g a.i./ha), carbosulfan (30 g a.i./ha), and bifenthrin (150 g a.i./ha). A control was included. Each treatment was performed in a $90 \mathrm{~m} \times 16 \mathrm{~m}$ area, with $10 \mathrm{~m}$ between each test as a buffer zone. Each treatment was comprised of three replicates.

\subsection{Characterization of Droplet Deposition}

The droplet deposition test was arranged in the T1-T9 treatment areas. Allura red (Roha Dyechem Shanghai Co., Ltd, Shanghai, China, $150 \mathrm{~g}$ a.i./ha) was used as a tracer and Kromekote cards (Elifo paper Co., Ltd, Beijing, China) were used as droplet test cards $^{[27]}$. The Kromekote cards were fixed on the upper side and underside of cotton leaves to analyze the distribution of droplet deposition. The Kromekote cards were placed at equal intervals, as shown in Figure 2. There were 8 sample points, and the lateral interval (perpendicular to the line of the flight) was $1 \mathrm{~m}$. Three lateral direction sampling lines were selected according to the previous method ${ }^{[15,28]}$, each having a longitudinal interval of $20 \mathrm{~m}$. There were a total of 48 Kromekote cards in the spraying area.

After each experiment, the Kromekote cards were detached and placed in a self-sealing bag 10 minutes after spraying. The Kromekote cards were then scanned with a flatbed scanner and the resulting images were analyzed using the Deposit-Scan software (USDA-ARS Application Technology Research Unit, Wooster, Ohio, USA, Deposit Scan 1.0). Spray quality was assessed by analyzing droplet coverage, density, distribution uniformity, and droplet size ${ }^{[27]}$. The size of the droplets was measured by the volume median diameter (VMD), as described in previous research $^{[18]}$. The coefficient of variation $(\mathrm{CV})$ was employed to measure the distribution uniformity of the spray deposition ${ }^{[29]}$, based on equations (1) and (2).

$$
\begin{gathered}
C V=\frac{S}{\bar{X}} \times 100 \% \\
S=\sqrt{\frac{\sum_{i=1}^{n}\left(X_{i}-\bar{X}\right)^{2}}{n-1}}
\end{gathered}
$$

where, $S$ is the standard deviation; $X_{i}$ is the droplet coverage per square centimeter of Kromekote card; $\bar{X}$ is the average droplet coverage per square centimeter of Kromekote card, and $n$ is the total number of Kromekote cards on each side of the cotton leaves in each treatment group.

\subsection{Control of Cotton Aphids}

Forty cotton plants were selected from each treatment zone and were tagged at five sampling points ( 8 cotton plants per point). The number of cotton aphids on each cotton plant was recorded prior to treatment. Aphids were counted on the same tagged plant at 1, 3, and 7 days after spraying. The dropping rate and control efficacy were obtained based on the population of live pests in each zone before spraying and after spraying, according to the following equation:

$$
R(\%)=\frac{B-A}{B} \times 100
$$


where, $R$ is the dropping rate of insects; $B$ is the number of live insects before spraying, and $A$ is the number of live insects after spraying.

$$
C E(\%)=\frac{R t-R c}{100-R c} \times 100
$$

where, $C E$ is the control efficacy; $R t$ is the dropping rate of insects in the treatment area (\%), and $R c$ is the dropping rate of insects in the control treatment area (\%).

\subsection{Statistical Analysis}

All statistical analysis was performed using SPSS 16.0 statistical analysis software (IBMSPSS Inc., Chicago, IL, USA). The control efficacy was arcsine-square-root transformed prior to statistical analysis; the droplet data collected from the upper side of cotton leaves were log-transformed; data collected on the underside of leaves were square-root transformed; and others were $\log$ $(x+1)$-transformed to improve the homogeneity of variance. All data were then subjected to analysis of variance (one-way ANOVA) and means were compared using Duncan's new multiple range test at 5\% probability. Origin Pro 8.0 software (Academic) (Origin Lab, USA) was used to show these values.

\section{Results}

\subsection{Effects of UAV spraying on droplet deposition}

\subsubsection{Droplet coverage and uniformity}

We compared the droplet coverage on the upper side and underside of cotton leaves between different treatments (Table 2). The results demonstrated that there was no significant difference in the coverage on the upper side of leaves, however, the difference on the underside was quite obvious. Among of these treatments, T5 operated at $1.5 \mathrm{~m}$ height and $22.5 \mathrm{~L} /$ ha had the maximum coverage $(10.14 \%)$. At a flight height of 1.0 or $2.0 \mathrm{~m}$, droplet coverage was correlated with spray volume and decreased as volume decreased. T5 had the highest total average coverage (9.79\%), while the average coverages of T3 $(4.44 \%)$, T6 (5.63\%), and T9 $(5.82 \%)$ were significantly lower, indicating that a lower spray volume $(18.0 \mathrm{~L} / \mathrm{ha})$ results in poor droplet coverage. In most cases, there was little difference between different flight heights when they sprayed the same volume of pesticide. Our results demonstrated that UAV operating height had little effect on droplet coverage.

The coefficient of variation was used to evaluate the distributional uniformity of droplet coverage. The smaller the CV is, the more well-distributed the droplets ${ }^{[30]}$. At a flight height of
$1.5 \mathrm{~m}$, the respective coverage $\mathrm{CVs}$ for $\mathrm{T} 4, \mathrm{~T} 5$, and $\mathrm{T} 6$ were $69.1 \%, 57.3 \%$, and $82.1 \%$, all of which were lower than treatments at flight heights of 1.0 and $2.0 \mathrm{~m}$. Therefore, flight heights of $1.5 \mathrm{~m}$ had better uniformities than flight heights of 1.0 and $2.0 \mathrm{~m}$. The best uniformity was achieved at $\mathrm{T} 5$, which had a $\mathrm{CV}$ value of $57.30 \%$.

Table 2 The droplet coverage on cotton leaves and uniformity of coverage

\begin{tabular}{ccccc}
\hline \multirow{2}{*}{$\begin{array}{c}\text { Treatment } \\
(\text { height } / \mathrm{m}, \\
\left.\text { volume } / \mathrm{L} h a^{-1}\right)\end{array}$} & Dpper side & Underside & $\begin{array}{c}\text { Average } \\
\text { droplet } \\
\text { coverage }\end{array}$ & $\begin{array}{c}\text { Coefficient of } \\
\text { variation } \\
(\mathrm{CV}) / \%\end{array}$ \\
\cline { 2 - 5 } T1 $(1.0,30.0)$ & $11.60 \pm 2.49 \mathrm{a}$ & $7.16 \pm 1.01 \mathrm{~b}$ & $9.38 \pm 1.37 \mathrm{ab}$ & 100.85 \\
T2 $(1.0,22.5)$ & $8.34 \pm 1.22 \mathrm{a}$ & $4.09 \pm 0.67 \mathrm{~cd}$ & $6.21 \pm 0.75 \mathrm{bc}$ & 84.03 \\
T3 $(1.0,18.0)$ & $6.90 \pm 0.76 \mathrm{a}$ & $1.99 \pm 0.20 \mathrm{de}$ & $4.44 \pm 0.53 \mathrm{c}$ & 82.69 \\
T4 $(1.5,30.0)$ & $6.76 \pm 1.21 \mathrm{a}$ & $7.09 \pm 0.70 \mathrm{~b}$ & $6.93 \pm 0.69 \mathrm{~b}$ & 69.10 \\
T5 $(1.5,22.5)$ & $9.43 \pm 1.46 \mathrm{a}$ & $10.14 \pm 0.73 \mathrm{a}$ & $9.79 \pm 0.81 \mathrm{a}$ & 57.30 \\
T6 $(1.5,18.0)$ & $8.85 \pm 0.90 \mathrm{a}$ & $2.42 \pm 0.32 \mathrm{de}$ & $5.63 \pm 0.67 \mathrm{c}$ & 82.10 \\
T7 $(2.0,30.0)$ & $9.02 \pm 2.06 \mathrm{a}$ & $8.42 \pm 1.50 \mathrm{~b}$ & $8.72 \pm 1.26 \mathrm{ab}$ & 100.23 \\
T8 $(2.0,22.5)$ & $9.17 \pm 1.06 \mathrm{a}$ & $5.83 \pm 1.20 \mathrm{bc}$ & $7.5 \pm 0.83 \mathrm{~b}$ & 76.36 \\
T9 $(2.0,18.0)$ & $9.46 \pm 1.38 \mathrm{a}$ & $2.18 \pm 0.414 \mathrm{e}$ & $5.82 \pm 0.89 \mathrm{c}$ & 105.68 \\
\hline
\end{tabular}

Note: The data in the table are mean \pm SE. Data with different small letters in the same column are significantly different at the 0.05 level by Duncan's new multiple range test.

\subsubsection{Droplet density}

The number of droplets per unit area varied with flight heights and spray volumes on both sides of leaves (Figure 3). On the upper side, droplet densities of T8 $\left(140.00\right.$ droplets $\left./ \mathrm{cm}^{2}\right)$ and T9 (145.24 droplets $\left./ \mathrm{cm}^{2}\right)$ were higher than those of T2 $(83.19$ droplets $\left./ \mathrm{cm}^{2}\right)$ and $\mathrm{T} 7$ (94.62 droplets $\left./ \mathrm{cm}^{2}\right)$. No significant differences were observed in the other treatments. For the underside, droplet density decreased as spray volume decreased at each height. When the flight height was $1.0 \mathrm{~m}$, the droplet densities of $30.0 \mathrm{~L} / \mathrm{ha}\left(101.40\right.$ droplets $/ \mathrm{cm}^{2}$ for $\left.\mathrm{T} 1\right)$ and $22.5 \mathrm{~L} / \mathrm{ha}$ (82.15 droplets $/ \mathrm{cm}^{2}$ for T2) were not significantly different from each other but were significantly higher than $18.0 \mathrm{~L} / \mathrm{ha}$ (44.49 droplets $/ \mathrm{cm}^{2}$ for $\mathrm{T} 3$ ). Similar trends were observed at flight heights of 1.5 and $2.0 \mathrm{~m}$. When the data from each volume were analyzed separately, the droplet density at a flight height of $1.5 \mathrm{~m}$ was higher than the droplet density at flight heights of 1.0 and $2.0 \mathrm{~m}$. The strong vertical winds generated by the UAV rotors at a lower altitude $(1.0 \mathrm{~m})$ and the drift of smaller droplets when sprayed at a higher altitude $(2.0 \mathrm{~m})$ could account for the decreases in droplets density at these heights.

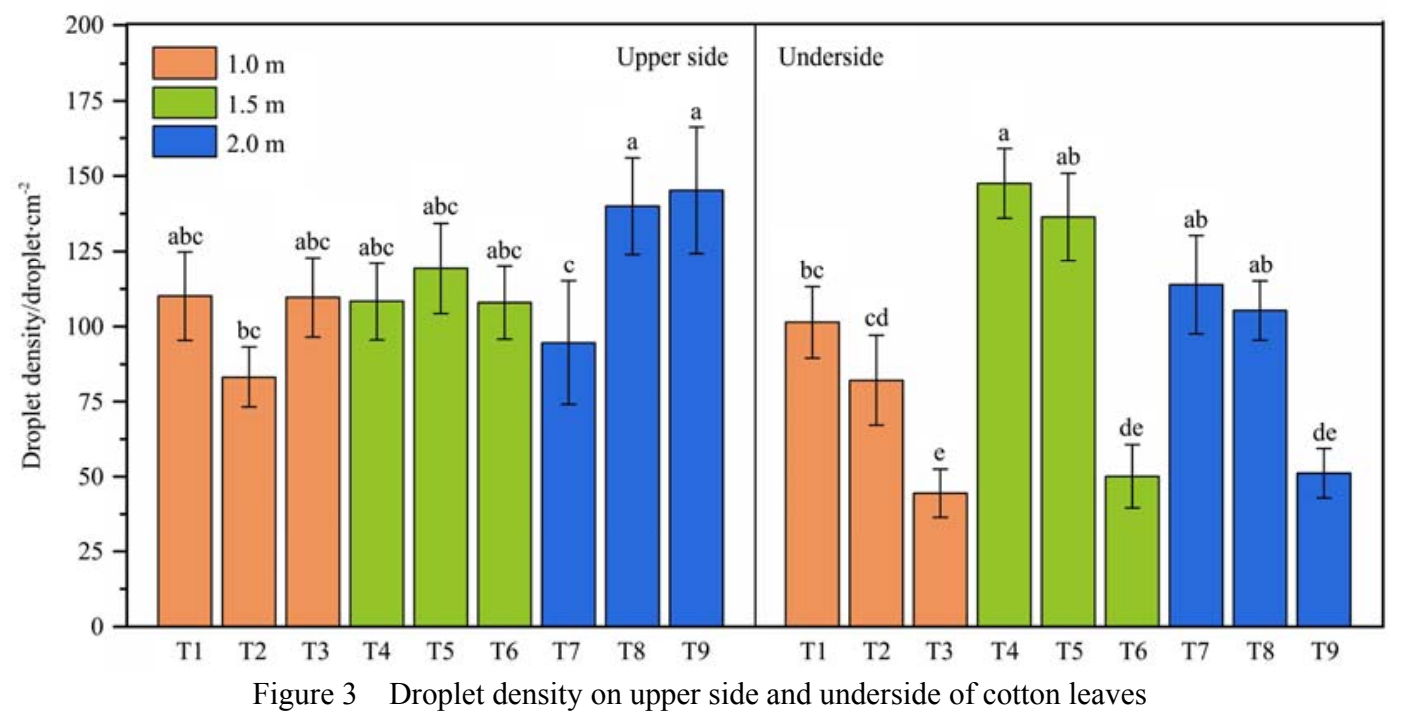




\subsubsection{Droplet size distribution}

To further assess droplet distribution, the droplet size on the upper side and underside of cotton leaves was compared (Figure 4). For the upper side, the maximum value, minimum value, and average value of droplet VMD were 302.67, 242.83, and $276.98 \mu \mathrm{m}$, respectively. For the underside, the maximum value, minimum value, and average value of droplet VMD were 237.25,
173.58, and $206.79 \mu \mathrm{m}$, respectively. Overall, our results demonstrated that more small droplets were deposited on the underside than on the upper side. In most cases, droplet size increased as spray volume increased. Larger VMD droplets occurred at T1, T5, and T7, which could be due to high levels of droplet deposition and subsequent overlap.

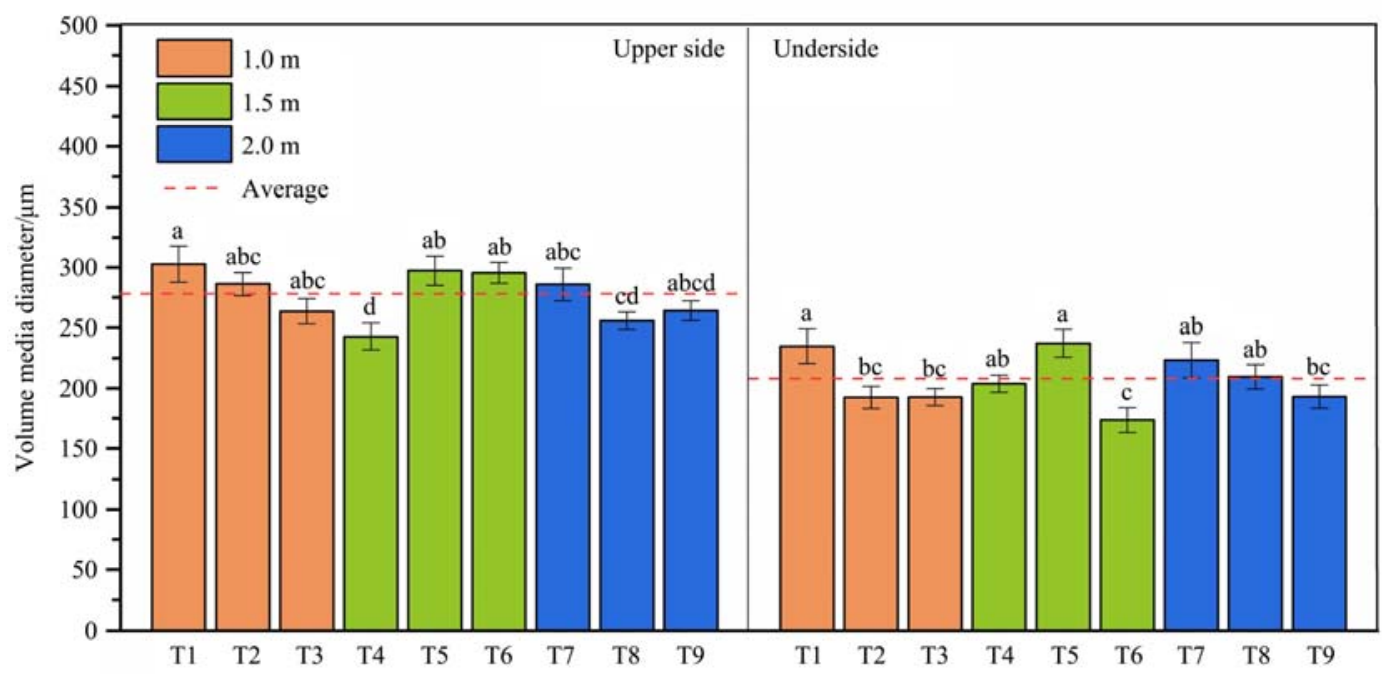

Figure 4 The volume media diameter (VMD) of droplets on upper side and underside of cotton leaves

\subsection{Control effect of cotton aphids}

In 2019, the control efficacy of cotton aphids was evaluated 1, 3 , and 7 days after treatment (Figure 5). For the MAP spray treatment, the control efficacy on the first day was $86.89 \%$. However, for UAV spray treatments, control efficacy rates varied $(42.04 \%$ to $78.92 \%)$. At similar flight heights, there was no significant difference between the control effect on cotton aphids at $30.0 \mathrm{~L} / \mathrm{ha}$ (T1, T4, and $\mathrm{T} 7$ ) and at $22.5 \mathrm{~L} / \mathrm{ha}(\mathrm{T} 2$, T5, and T8), while there was a significant difference between the volumes of 30.0 and $18.0 \mathrm{~L} / \mathrm{ha}$ (T3, T6, and T9). Therefore, control efficacy decreased as spray volume decreased. The number of droplets deposited on the target was a crucial factor determining pesticide efficiency. At a volume of $18.0 \mathrm{~L} / \mathrm{ha}$, the lower control efficacy could be due to less droplet deposition on the leaves (Table 2 and Figure 3). The control efficacy of most treatments improved three days after application, however, the control efficacy of $18.0 \mathrm{~L} / \mathrm{ha}$ treatments $(51.22 \%$ for T6 and $44.63 \%$ for T9) was still lower than that of other treatments. On the seventh day, the control efficacy of the UAV sprayer ranged from $47.63 \%$ to $80.53 \%$, which was not significantly different from that of the MAP sprayer. The best control efficacy using the UAV sprayer was achieved at 1.0 and $1.5 \mathrm{~m}$.

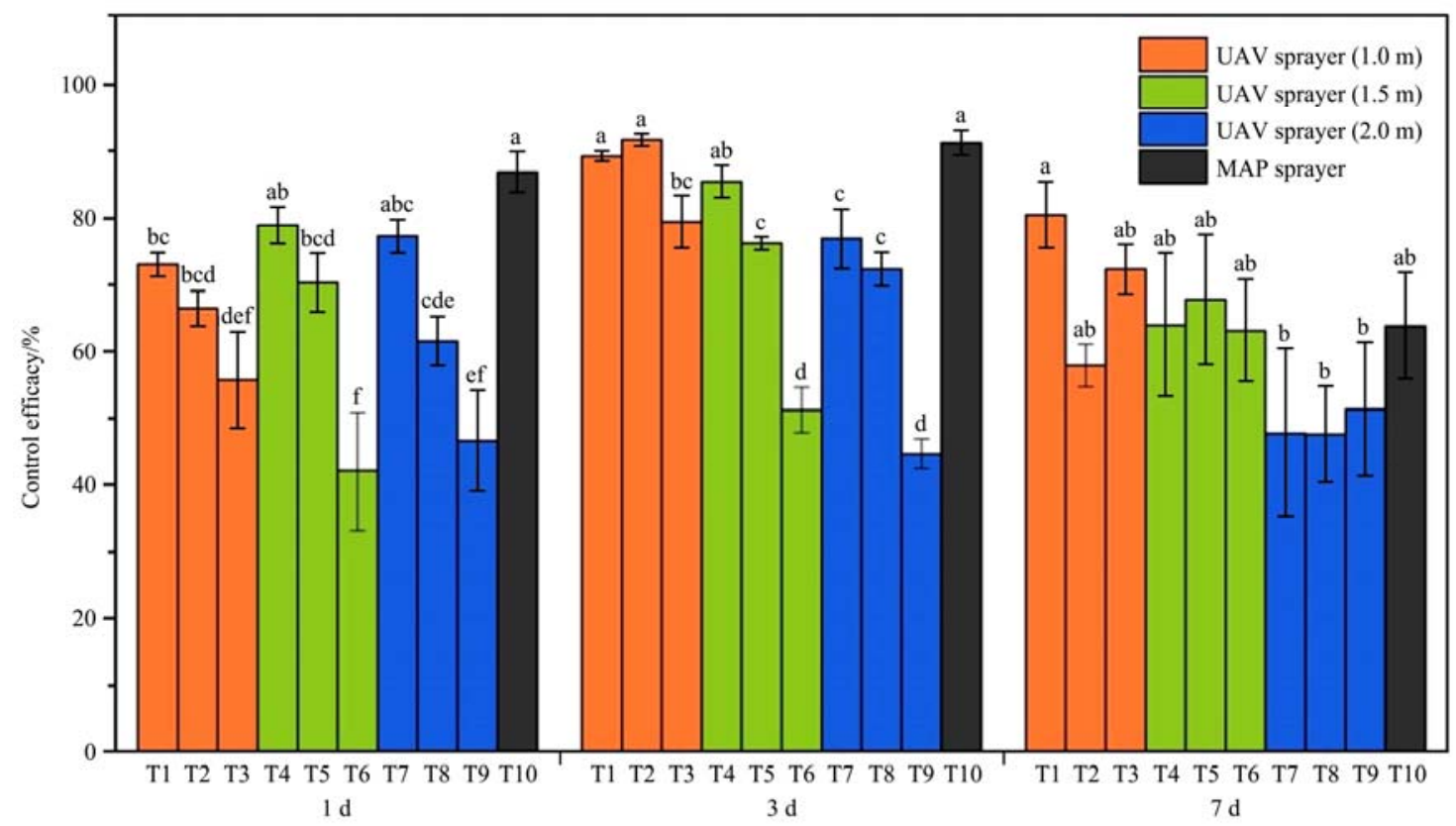

Figure 5 Effects of Imidacloprid and Beta-cypermethrin on cotton aphid control sprayed by UAV and MAP sprayer.

Data in the figure are mean \pm SE. Bars with different letters are significantly different at $p<0.05$, according to Duncan's multiple range test.

\subsection{Effects of insecticides sprayed by UAV}

The control efficacy of five insecticides on cotton aphids was evaluated 1, 3, and 7 days following UAV spraying (Table 3). In 2019 , the control efficacies of all treatments on the first day after 
spraying varied from $45.27 \%$ to $61.90 \%$. Seven days after spraying, the control efficacies of all treatments exceeded $67 \%$, while the best control efficacy $(87.80 \%)$ was achieved using sulfoxaflor. In 2020 , the control efficacies of all treatments on the first day after treatment ranged from $46.23 \%$ to $58.24 \%$. Seven days after spraying, the control efficacies of sulfoxaflor and flonicamid-acetamiprid exceeded $90 \%$, which were significantly higher than other treatments. These results demonstrated that applying all five insecticides via UAV (at a flight height of $1.5 \mathrm{~m}$ and a spray volume of $22.5 \mathrm{~L} / \mathrm{ha}$ ) effectively controlled cotton aphids. The control efficacy of sulfoxaflor was comparable to flonicamid-acetamiprid and was better than thiamethoxam and bifenthrin.

Table 3 Control efficacy of different insecticides against cotton aphids

\begin{tabular}{|c|c|c|c|c|c|c|}
\hline Year & Date & Thiamethoxam & Sulfoxaflor & Flonicamid acetamiprid & Carbosulfan & Bifenthrin \\
\hline \multirow{3}{*}{2019} & $1 \mathrm{~d}$ & $48.69 \pm 2.41 \mathrm{a}$ & $45.27 \pm 7.85 \mathrm{a}$ & $61.90 \pm 2.91 \mathrm{a}$ & $61.62 \pm 7.52 \mathrm{a}$ & $53.58 \pm 8.69 a$ \\
\hline & $3 \mathrm{~d}$ & $81.79 \pm 3.46 \mathrm{~b}$ & $90.95 \pm 2.81 \mathrm{a}$ & $90.55 \pm 1.63 \mathrm{a}$ & $88.03 \pm 1.86 \mathrm{ab}$ & $87.11 \pm 1.90 \mathrm{ab}$ \\
\hline & $7 \mathrm{~d}$ & $67.71 \pm 3.00 \mathrm{c}$ & $87.80 \pm 2.79 \mathrm{a}$ & $82.23 \pm 4.93 \mathrm{ab}$ & $75.51 \pm 5.49 \mathrm{abc}$ & $73.61 \pm 3.34 \mathrm{bc}$ \\
\hline \multirow[b]{2}{*}{2020} & $1 \mathrm{~d}$ & $50.29 \pm 4.62 \mathrm{ab}$ & $57.34 \pm 4.05 \mathrm{ab}$ & $58.24 \pm 0.99 \mathrm{a}$ & $53.88 \pm 3.08 \mathrm{a}$ & $46.23 \pm 2.12 b$ \\
\hline & $3 \mathrm{~d}$ & $73.19 \pm 1.39 \mathrm{bc}$ & $83.74 \pm 2.40 \mathrm{a}$ & $86.25 \pm 0.16 \mathrm{a}$ & $76.49 \pm 0.61 \mathrm{~b}$ & $68.61 \pm 0.82 \mathrm{c}$ \\
\hline
\end{tabular}

Note: The data in the table are mean \pm SE. Data with different small letters in the same column are significantly different at the 0.05 level by Duncan's new multiple range test.

\section{Discussion}

Droplet coverage and droplet uniformity are important factors affecting spray quality ${ }^{[10,27,29]}$. In this study, the coefficient of variance of droplet coverage was used to evaluate the distribution of UAV spraying. Our results demonstrated that the distribution and uniformity of droplets varied with UAV flight height and spray volume. In most cases, the average droplet coverage increased as spray volume increased, while higher-volume sprays $(30.0 \mathrm{~L} / \mathrm{ha})$ resulted in low droplet uniformity. At a fixed spray volume, flight heights that were too low $(1 \mathrm{~m})$ or too high $(2 \mathrm{~m})$ also led to poor uniformity. This could be because wind generated by the UAV rotors above the cotton canopy (at flight heights of $1.0 \mathrm{~m}$ ) was strong enough to affect droplet deposition on the leaves. On the contrary, at a flight height of $2 \mathrm{~m}$ the droplets were carried by the wind to an off-target area. Lou et al. studied the effect of UAV flight height on droplet distribution and drift in cotton, and found that the average drift percentage at $2.0 \mathrm{~m}(20 \%)$ was much higher than that at $1.5 \mathrm{~m}(7.9 \%)^{[31]}$. Overall, a flight height of $1.5 \mathrm{~m}$ and a spray volume of $22.5 \mathrm{~L} /$ ha resulted in the maximum deposition and optimal uniformity of droplets on the targets. Therefore, a flight height of $1.5 \mathrm{~m}$ and a spray volume of $22.5 \mathrm{~L} / \mathrm{ha}$ are the optimal parameters for UAV spraying.

Droplet size and the number of droplets are also important factors to consider when assessing UAV spray quality ${ }^{[10,27,32]}$. Analysis of droplet density demonstrated that the number of droplets deposited on the leaves, especially on the underside, was affected by both flight height and spray volume. At each flight height, droplet densities of 30.0 and $22.5 \mathrm{~L} /$ ha did not differ, but were significantly higher than at treatments of $18.0 \mathrm{~L} / \mathrm{ha}$. This is consistent with the conclusions of previously published research $^{[23,33]}$, which demonstrated that droplet density increased as spray volume increased. In general, $1.5 \mathrm{~m}$ treatments performed better than 2.0 and $1.0 \mathrm{~m}$ treatments. This could be because droplets drift at $2.0 \mathrm{~m}$ and winds generated by the rotors affect droplets at $1.0 \mathrm{~m}$. Our results were similar to the results of Lou et $\mathrm{al}^{[31]}$. Previous research studied the parameters that influence spraying effects and found that fine droplets $(<50 \mu \mathrm{m})$ are inclined to drift to the air, while coarser droplets $(>400 \mu \mathrm{m})$ have difficulty passing through the canopies of crops ${ }^{[10,33,34]}$. The optimal size of the droplets of UAV spraying is $50-300 \mu \mathrm{m}^{[35,36]}$. Our results demonstrated that the droplet sizes used in this experiment are within the optimal droplet size range, while smaller droplets are more likely to settle on the underside of cotton leaves and larger droplets are more likely to settle on the upper side of cotton leaves. This could be due to downward air flow and crosswinds, which tilt the plant and turn the leaves ${ }^{[18]}$. Under these conditions, smaller droplets could easily be deposited on the underside of cotton leaves.

The efficacy of pesticide application is related to the number of droplets accumulating on the pests and leaves of the target crop. A greater droplet density typically has a higher probability of reaching the critical threshold for pest control ${ }^{[27,33]}$. Our results demonstrated that control efficacy is influenced by spray volume and flight height. On the first day following pesticide application, control efficacy decreased as spray volume decreased. Cotton aphids tend to favor leaf bottoms, and our results demonstrated that the control effect was correlated with the number of droplets deposited on the leaves. At similar levels of pesticide application, spraying larger volumes resulted in higher droplet deposition densities, which could account for the optimal control efficacy at 22.5 and $30.0 \mathrm{~L} / \mathrm{ha}$. Meng et al. explored how applying aerial pesticides via UAV affected the control efficacy of wheat aphids, and found that when the average droplet density increased from 82.33 to 136.80 droplets $/ \mathrm{cm}^{2}$, the control efficacy increased from $69.05 \%$ to $81.68 \%{ }^{[37]}$. Chen et al. studied the influence of nozzle size on droplet deposition and the subsequent control effects on plant hopper and found that the control effect was better when the droplet density on the leaves was higher ${ }^{[19]}$. Wang et al. found similar results when spraying pesticides with UAVs to control wheat aphids ${ }^{[23]}$. The results obtained in our experiment are consistent with both of these studies. In this study, the first-day control efficacy of imidacloprid and beta-cypermethrin could be due to contact toxicity. Three days after the pesticides were applied, the control efficacies of most treatments increased. This could be due to the stomach poisoning and systemic action of the pesticides. While no significant difference was observed on the seventh day after the pesticides were applied, the control efficacy of UAV spraying operating at $2.0 \mathrm{~m}$ was slightly lower than for other treatments. Therefore, the working height of the UAV influenced the control effect.

After considering work efficiency, deposition, and droplet uniformity, a flight height of $1.5 \mathrm{~m}$ and a spray volume of $22.5 \mathrm{~L} / \mathrm{ha}$ were chosen for pesticide spraying, and field trials of all five insecticides demonstrated positive control effects against cotton aphids. Moreover, the results also showed that control efficacy 
was likely correlated with the mechanism action of pesticide. Bifenthrin is a traditional pyrethroid insecticide and is toxic to pests when they touch or ingest $\mathrm{it}^{[38]}$. Thiamethoxam is a traditional neonicotinoid insecticide widely used in insect control ${ }^{[39]}$. However, in recent years, the widespread use of bifenthrin and thiamethoxam has resulted in insecticide resistance in cotton aphids $^{[40,41]}$. In this study, the seventh-day control efficacy of bifenthrin and thiamethoxam was lower than for other pesticides. In contrast, the control efficacy of sulfoxaflor, a new neonicotinoid insecticide ${ }^{[42]}$, was much higher, and our results demonstrated that it is an acceptable substitute for bifenthrin and thiamethoxam.

The cotton aphid Aphis gossypii Glover is a phloem-feeding pest that gathers on the underside of leaves. Without proper controls, this pest can transmit viruses and stunt plant growth, resulting in huge economic losses ${ }^{[43]}$. Our research demonstrated that UAV flight height and spray volume could affect the deposition and distribution of droplets on both upside and underside of cotton leaves. Droplet deposition also influences the ability of pesticides to control aphids. At a UAV spray volume of $18.0 \mathrm{~L} / \mathrm{ha}$, the average droplet coverage and density on the upper side of leaves was $8.40 \%$ and 120.93 droplets $/ \mathrm{cm}^{2}$, respectively, while the deposition on the underside were $2.20 \%$ and 48.58 droplets $/ \mathrm{cm}^{2}$, respectively. However, identifying mechanisms for improving spray quality and increasing droplet deposition on target leaves requires further research.

\section{Conclusions}

This study used a UAV sprayer and a manual sprayer to apply pesticides to seedling-stage cotton to control aphids and assessed how different flight heights and spray volumes affected droplet deposition and the overall control effect on cotton aphids. Results demonstrated that droplet distribution and uniformity varied with UAV flight height and spray volume. The difference in droplet coverage on the upper side of cotton leaves did not significantly differ between treatments, while the difference in droplet coverage on the underside of cotton leaves was significant. The maximum average droplet coverage $(9.79 \%)$ and optimal droplet uniformity were achieved at a flight height of $1.5 \mathrm{~m}$ and a spray volume of $22.5 \mathrm{~L} / \mathrm{ha}$, with a CV of $57.30 \%$. The droplet density on the upper side and underside of the leaves was influenced by spray volume. The aphid control efficacy on the 1st day after spraying was correlated with droplet density; a higher droplet density on the underside of cotton had a better control effect, and a lower droplet density had a poor control effect. Flight height influenced the control effect when assessed on the seventh day: the control efficacy of UAV treatments operating from $1 \mathrm{~m}$ to $1.5 \mathrm{~m}$ ranged from $57.93 \%$ to $80.53 \%$, while the control efficacy at $2 \mathrm{~m}$ ranged from $47.63 \%$ to $51.27 \%$. In 2019 , the control efficiencies of the five insecticides varied from $67.71 \%$ to $87.80 \%$, and in 2020 , efficiencies varied from $71.88 \%$ to $92.18 \%$. After assessing spraying effect, control efficacy, and the control effects of insecticides, a flight height of $1.5 \mathrm{~m}$ and a spray volume of $22.5 \mathrm{~L} / \mathrm{ha}$ are the optimal parameters for UAV spraying to control aphids in seedling-stage cotton.

\section{Acknowledgments}

The authors are grateful to Anyang Quanfeng Biological Technology Co., Ltd. for providing UAVs and insecticides.

\section{Author Contributions}

Hongyan Hu and Yan Ma contributed to the study conception and design. Material preparation, investigation, data collection, and analysis were performed by all authors. The first draft of the manuscript was written by Hongyan Hu, with review and editing by Yanhua Meng and Xiaoyan Ma. All authors have read and agreed to publish this version of the manuscript.

\section{Funding}

This research was funded by the National Natural Science Foundation of China (31801751), the National Key Research and Development Program of China (2016YFD0200700), the Central Public-interest Scientific Institution Basal Research Fund (1610162021029), and the Agricultural Science and Technology Innovation Program of Chinese Academy of Agricultural Sciences.

\section{Conflicts of Interest}

The authors declare no conflict of interest.

\section{[References]}

[1] Ye W W. Cotton breeding research progress in China. New Biotechnology, 2014; 31(supplement): S168. doi: 10.1016/j.nbt.2014.05.2038.

[2] Wu K M, Lu Y H, Feng H Q, et al. Suppression of cotton bollworm in multiple crops in China in areas with Bt toxin-containing cotton. Science, 2008; 321(5896): 1676-1678. doi: 10.1126/science.1160550.

[3] Meng Y H, Song J L, Lan Y B, et al. Harvest aids efficacy applied by unmanned aerial vehicles on cotton crop. Industrial Crops Products, 2019, 140(15): 111645. doi: 10.1016/j.indcrop.2019.111645.

[4] Xin F, Zhao J, Zhou Y T, et al. Effects of dosage and spraying volume on cotton defoliants efficacy: a case study based on application of Unmanned Aerial Vehicles. Agronomy, 2018; 8(6): 85 . doi: 10.3390/agronomy8060085.

[5] Li Y J, Li Y F, Pan X, et al. Comparison of a new air-assisted sprayer and two conventional sprayers in terms of deposition, loss to the soil and residue of azoxystrobin and tebuconazole applied to sunlit greenhouse tomato and field cucumber. Pest Management Science, 2017; 74(2): 448-455. doi: 10.1002/ps.4728.

[6] Wang G B, Lan Y B, Yuan H Z, et al. Comparison of spray deposition, control efficacy on wheat aphids and working efficiency in the wheat field of the unmanned aerial vehicle with boom sprayer and two conventional knapsack sprayers. Applied Sciences, 2019; 9(2): 218 . doi: 10.3390/app9020218.

[7] Zhang W J, Jiang F B, Ou J F. Global pesticide consumption and pollution: with China as a focus. Proceeding of the International Academy of Ecology and Environmental Sciences, 2011; 1(2): 125-144.

[8] Chen S D, Lan Y B, Li J Y, et al. Comparison of the pesticide effects of aerial and artificial spray applications for rice. Journal of South China Agricultural University, 2017; 38(4): 103-109. doi: 10.7671/ j.issn.1001-411X.2017.04.017. (In Chinese)

[9] Psirofonia P, Samaritakis V, Eliopoulos P, et al. Use of Unmanned aerial vehicles for agricultural applications with emphasis on crop protection: three novel case-studies. International Journal of Agricultural Science and Technology, 2017; 5(1): 30-39. doi: 10.12783/ ijast.2017.0501.03

[10] Ahmad F, Qiu B J, Dong X Y, et al. Effect of operational parameters of UAV sprayer on spray deposition pattern in target and off-target zones during outer field weed control application. Computers and Electronics in Agriculture, 2020; 172: 105350. doi: 10.1016/j.compag.2020.105350

[11] Richardson B, Rolando C A, Somchit C, et al. Swath pattern analysis from a multi-rotor unmanned aerial vehicle configured for pesticide application. Pest Management Science, 2019; 76(4): 1282-1290. doi: $10.1002 /$ ps.5638

[12] Zhang D Y, Lan Y B, Chen L P, et al. Current status and future trends of agricultural aerial spraying technology in China. Transaction of the Chinises Society for Agricultural Machinery, 2014; 45(10): 53-59. doi: 10.6041/j.issn.1000-1298.2014.10.009. (in Chinese)

[13] Yang S L, Yang X B, Mo J Y. The application of unmanned aircraft systems to plant protection in China. Precision Agriculture, 2018; 19(2): 278-292. doi: 10.1007/s11119-017-9516-7.

[14] Bae Y, Koo Y M. Flight attitudes and spray patterns of a roll-balanced 
agricultural unmanned helicopter. Applied Engineering in Agriculture, 2013; 29(5): 675-682. doi: 10.13031/aea.29.10059.

[15] Qin W C, Qiu B J, Xue X Y, et al. Droplet deposition and control effect of insecticides sprayed with an unmanned aerial vehicle against plant hoppers. Crop Protection, 2016; 85: 79-88. doi: 10.1016/ j.cropro.2016.03.018.

[16] Qiu B J, Wang L W, Cai D L, et al. Effects of flight altitude and speed of unmanned helicopter on spray deposition uniform. Transaction of the Chinese Society Agricultural Engineering, 2013; 29(24): 25-32. doi: 10.3969/j.issn.1002-6819.2013.24.004. (in Chinese)

[17] Oliveira M A P, Antuniassi U R, Velini E D, et al. Influence of spray mixture volume and flight height on herbicide deposition in aerial applications on pastures. Planta Daninha, 2014; 32(1): 227-232. doi: 10.1590/S0100-83582014000100025

[18] Tang Y, Hou C J, Luo S M, et al. Effects of operation height and tree shape on droplet deposition in citrus trees using an unmanned aerial vehicle. Computers and Electronics in Agriculture, 2018; 148: 1-7. doi: 10.1016/ j.compag.2018.02.026.

[19] Chen P C, Lan Y B, Huang X Y, et al. Droplet deposition and control of planthoppers of different nozzles in two-stage rice with a quadrotor unmanned aerial vehicle. Agronomy, 2020; 10(2): 303. doi: 10.3390/ agronomy10020303.

[20] Hussain S, Cheema M J M, Arshad M, et al. Spray uniformity testing of unmanned aerial spraying system for precise agro-chemical applications. Pakistan Journal of Agricultural Sciences, 2019; 56(4): 897-903. doi: 10.21162/PAKJAS/19.8594.

[21] Gao Y Y, Zhang Y T, Zhao Y C, et al. Primary studies on spray droplet distribution and control effects of aerial spraying using unmanned aerial (UAV) against the corn borer. Plant Protection, 2013; 39(2): 152-157. doi: 10.3969/j.issn.0529-1542.2013.02.031. (in Chinese)

[22] Menechini W, Maggi M F, Jadoski S O, et al. Aerial and ground application of fungicide in corn second crop on diseases control. Engenharia Agricola, 2017; 37(1): 116-127. doi: 10.1590/ 1809-4430-eng.agric.v37n1p116-127/2017.

[23] Wang G B, Lan Y B, Qi H X, et al. Field evaluation of an unmanned aerial vehicle (UAV) sprayer: effect of spray volume on deposition and the control of pests and disease in wheat. Pest Management Science, 2019; 75(6): 1546-1555. doi: 10.1002/ps.5321.

[24] Wang Z, Feng H Z, Ma X Y, et al. Efficacy of insecticide spray drone on Aphis gossypii control and the benefit evaluation. Chinese Journal of Pesticide Science, 2019; 21(3): 366-371. doi: 10.16801/ j.issn.1008-7303.2019.0043. (in Chinese)

[25] Wu J L, Feng H Z, Ma X Y, et al. Screening of Fly control agents for cotton aphid in cotton fields in Xinjiang and preliminary report of pesticide reduction and efficiency improvement. Xinjiang Agricultural Sciences, 2020; 57(1): 167-172. doi: 10.6048/j.issn.1001-4330.2020.01.019. (in Chinese)

[26] Sha S S, Wang Z, Xiao H B, et al. Optimizing operation parameters of an unmanned aerial vehicle P20 and its application effects for spraying insecticides to control cotton aphid. China cotton, 2018; 45(1): 6-8. doi: 10.11963/1000-632X.ssswl.20171211. (in Chinese)

[27] Zhu H P, Salyani M, Foxa R D, et al. A portable scanning system for evaluation of spray deposit distribution. Computers and Electronic in Agriculture, 2011; 76(1): 38-43. doi: 10.1016/j.compag.2011.01.003.

[28] Qin W C, Xue X Y, Zhang S M, et al. Droplet deposition and efficiency of fungicides sprayed with small UAV against wheat powdery mildew. Internal Journal of Agricultural Biological Engineering, 2018; 11(2): 27-32. doi: 10.25165/j.ijabe.20181102.3157.

[29] Smith D B. Uniformity and recovery of broadcast spray using fan nozzles. Transactions of the ASAE, 1992; 35: 39-44.

[30] Guo S, Li J Y, Yao W X, et al. Distribution characteristics on droplet deposition of wind field vortex formed by multi-rotor UAV. PLoS ONE, 2019; 14(7): e0220024. doi: 10.1371/journal.pone.0220024.

[31] Lou Z X, Xin F, Han X Q, et al. Effect of unmanned aerial vehicle flight height on droplet distribution drift and control of cotton aphids and spider mites. Agronomy, 2018; 8(9): 187 . doi: 10.3390/agronomy8090187.

[32] Ferguson J C, Chechetto R G, Hewitt A J. Assessing the deposition and canopy penetration of nozzles with different spray qualities in an oat (Avena sativa L.) canopy. Crop Protection, 2016; 81: 14-19. doi: 10.1016/j.cropro.2015.11.013

[33] Yuan H Z, Wang G B. Effects of droplet size and deposition density on field efficacy of pesticides. Plant protection, 2015; 41(6): 9-16. doi: 10.3969/j.issn.0529-1542.2015.06.002. (in Chinese)

[34] Song J L, Qi L J, Sun X H, et al. Study on flying time and distribution characteristic of droplet from sprayer. Transactions of the Chinese Society of Agricultural Machinery, 2007; 38(4): 54-57. (in Chinese)

[35] Hewitt A J. Droplet size spectra classification categories in aerial application scenarios. Crop Protection, 2008; 27(9): 1284-1288. doi: 10.1016/j.cropro.2008.03.010.

[36] Zhang X Q, Song X P, Liang Y J, et al. Effects of spray parameters of drone on the droplet deposition in sugarcane canopy. Sugar Tech, 2020; 22(2): 1-6. doi: 10.1007/s12355-019-00792-z.

[37] Meng Y H, Lan Y B, Mei G Y, et al. Effect of aerial spray adjuvant applying on the efficiency of small unmanned aerial vehicle for wheat aphids control. International Journal of Agricultural and Biological Engineering, 2018; 11(5): 46-53. doi: 10.25165/j.ijabe.20181105.4298.

[38] Jones M M, Duckworth J L, Robertson J. Toxicity of bifenthrin and mixtures of bifenthrin plus acephate, imidacloprid, thiamethoxam, or dicrotophos to adults of tarnished plant bug (Hemiptera: Miridae). Journal of Econpmic Entomology, 2018; 111(2): 829-835. doi: 10.1093/jee/tox341.

[39] Bass C, Denholm I, Williamson M S, et al. The global status of insect resistance to neonicotinoid insecticides. Pesticide Biochemistry Physiology, 2015; 121: 78-87. doi: 10.1016/j.pestbp.2015.04.004.

[40] Herron G A, Wilson L J. Neonicotinoid resistance in Aphis gossypii Glover (Aphididae: Hemiptera) from Australian cotton. Australlian Journal of Entomology, 2011; 50(1): 93-98. doi: 10.1111/ j.1440-6055.2010.00788.x.

[41] Chen X W, Tie M Y, Chen A Q, et al. Pyrethroid resistance associated with M918 L mutation and detoxifying metabolism in Aphis gossypii from Bt cotton growing regions of China. Pest Management Science, 2017; 73(11): 2353-2359. doi: 10.1002/ps.4622.

[42] Siviter H, Brown M J F, Leadbeater E. Sulfoxaflor exposure reduces bumblebee reproductive success. Nature, 2018; 561(7721): 109-112. doi: 10.1038/s41586-018-0430-6.

[43] Ramalho F S, Fernandes F S, Nascimento A R B, et al. Feeding damage from cotton aphids, Aphis gossypii Glover (Hemiptera: Heterpptera: Aphididae), in cotton with colored fiber intercropped with fennel. Annals of the Entomological Society of America, 2012; 105(1): 20-27. doi: 10.1603/AN11122. 